\title{
New commissioner spells new direction for EU research funding
}

The EU's $€ 50.5$ billion ( $\$ 69.4$ billion) research framework is the biggest such fund in the world. But it is not known for being nimble, and it is underused by European businesses. Now, as the seven-year program approaches its half-time review, a change in the political lineup could lead to shifts in funding priorities that favor ambitious pan-European ideas.

Máire Geoghegan-Quinn, a former member of the Irish parliament, took office last month as European Commissioner for Research, Innovation and Science and will oversee a portfolio that combines for the first time all three areas. At her nomination hearing in January, she promised to make funding more accessible to business and to seek new backing for research.

"Refined knowledge will replace crude oil as the economy's prime motive force," Geoghegan-Quinn told a European parliamentary committee.

Geoghegan-Quinn's appointment will probably lead to a greater focus on translating basic biomedical research into treatments for diseases that affect many EU countries, says European Commission health research director Ruxandra Draghia-Akli. "There are a lot of data that are coming out of genomic, proteomic and metabolomic projects, and the data have to be exploited...with an eye towards personalized medicine."

The new commissioner will also be in a key position to shape the next framework program, slated for 2014-2020. Under the current Seventh Framework Program (FP7), $€ 6.1$ billion was earmarked for health research, though several European research funding streams touch on health issues. Official planning for FP8 begins later this year, and a proposal is due in early 2012.

Geoghegan-Quinn's appointment comes hot on the heels of EU member states ratifying the Treaty of Lisbon, which came into effect in December and represents the first European treaty to explicitly address research. At the same time, Brussels is preparing the Europe 2020 strategy, a document that will outline how to use Europe's research resources to achieve large societal goals. And, on 9 February, European science ministers meeting in San Sebastián, Spain issued a declaration of the importance of fully integrating research into the continent's economic strategy.
In this vein, Geoghegan-Quinn hinted in her hearing that more funds aimed at leveling the playing field among EU member states could be turned toward basic research funding, with coordination from Brussels. Currently, $€ 86$ billion of the so-called cohesion fund's $€ 347$ billion pot of cash goes toward research, innovation and enterprise projects, but this money is managed at a regional level. For example, Poland recently dipped into the fund to finance higher education and competitive research grants.

Such thinking may also be behind a multimillion-euro pilot, adopted in December to tackle Alzheimer's and other neurodegenerative diseases, that was jointly funded by several national research organizations, says Gunnar Sandberg, international collaboration coordinator for health, ideas and regions at Vinnova, the Swedish government agency for innovation in Stockholm. Joint programming between countries and across European funding streams should help further concentrate Europe's research resources on problems of common interest, he says.

Lucas Laursen, Madrid

\section{Researchers unite to improve Parkinson's drug discovery}

In recent years, dozens of new animal and cellular models of Parkinson's disease have helped researchers better understand the pathology of this neurological disorder. But none of these models accurately reproduces all the stages of disease progression, which has led to the field becoming fragmented among many camps working with many systems.

To foster synergies moving forward, the Michael J. Fox Foundation (MJFF) for Parkinson's Research in New York last month established an international consortium to focus on one of the most promising candidate drug targets of the neurodegenerative disease - a gene encoding leucine-rich repeat kinase-2 (LRRK2).

Under the terms of the two-year $\$ 3.5$ million grant design, members of the nine-group LRRK2 consortium, which includes both academic and industry partners, will be compelled to share results and collaborate with one another on an ongoing basis to help accelerate therapeutic discoveries. By working together, "every lab is not reinventing the wheel," says Todd Sherer, MJFF's vice president of research programs.

"You don't gain much by keeping things under wraps," says consortium member Patrick Lewis of University College London. "Actually getting different people with different viewpoints and different techniques to work together in an open fashion rapidly speeds up progress."

The first gene linked to Parkinson's, the gene encoding alpha-synuclein, was discovered more than a decade ago. Since then, researchers have created numerous genetic and toxic animal models of alphasynuclein accumulation, including a new one reported in January that was made by exposing mice to the pesticide rotenone (PLoS One 5, e8762, 2010). But "the field recognizes that none of these models are ideal," says Mike Sasner, director of the Parkinson's Disease Mouse Model Resource at the Jackson Laboratory in Bar Harbor, Maine, which now distributes 12 mouse strains that overexpress alpha-synuclein and has five more models under development. Moreover, none of these has yet led to any promising therapies.
The $L R R K 2$ gene was first linked to Parkinson's in 2004 and has since been implicated in more cases of Parkinson's than any other previously identified genetic risk factor, including variants in the gene encoding alpha-synuclein.

Elan Pharmaceuticals' Jennifer Johnston, who advises MJFF but is not part of the LRRK2 consortium, applauds the effort for greater coordination. "If everyone is using the same nuts and bolts, it makes things easier down the line," she says.

The MJFF is not the only charity to enforce such an approach, however. Last November, the Wellcome Trust and UK Medical Research Council also launched three multidisciplinary collaborations centered around neurodegenerative diseases, including one focused on dissecting the genetic and biochemical pathways of Parkinson's. This effort encourages researchers to "pool their expertise with a view to do something a little bit more high risk and creative," says Wellcome's senior neuroscience advisor Richard Morris.

Elie Dolgin, New York 